\title{
Errâncias racionais: a periferia, o RAP e a política
}

GIORDANO BARBIN BERTEL"

\section{Resumo}

Este artigo realiza uma reflexão acerca da dimensão política da estética do RAP. A partir de aspectos físicos e sociais do processo de expansão urbana e de periferização da cidade de São Paulo, procede-se à análise de trechos de composições do grupo de RAP Racionais MC's. Busca-se analisar a inserção de sua poética nos conflitos envolvidos no confrontamento entre "centro" e "periferia", enquanto categorias negociadas na dinâmica conflitiva de relações sociais do espaço urbano. Finaliza-se apontando - na tensão que se observa, por um lado, na relação do RAP com a ordem institucional do Estado, e, por outro, com a dinâmica do "mundo do crime" - o ponto social e poético em que reside a força e a ambiguidade do potencial político de sua estética.

Palavras-chave: Política. Estética. RAP. Ressignificação. Conflito.

\section{Rational wanderings: the periphery, the RAP and the politics}

\section{Abstract}

This article reflects on the political dimension of the aesthetics of RAP. The study focuses on both physical and social aspects of the processes of urban expansion and peripheralization in the city of São Paulo, based on the analysis of

\footnotetext{
"Mestre em Sociologia. Doutorando em Sociologia pelo Programa de Pós-Graduação em Sociologia da Universidade Federal de São Carlos. (Brasil). E-mail: giorbertelli@yahoo.com.br.
} 
excerpts of songs from the RAP group Racionais MCs. We seek to analyze the insertion of their poetry in confrontation between "center" and "periphery" as categories negotiated in the conflictive dynamics of social relations in the urban space. The article concludes noting the tensions established in the relations of RAP with, on the one hand, the institutional order of the State and, on the other hand, the dynamics of the "criminal world", and pointing out the social and the poetic features in which lie both the strength and the ambiguity of the political potential of its aesthetics.

Keywords: Politics. Aesthetics. RAP. Resignification. Conflict.

\section{Apresentação}

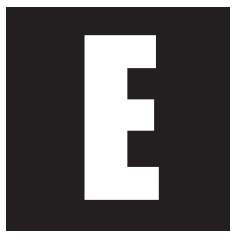

ste artigo busca situar-se na contramão de grande parte das posturas que o debate público atual tende a assumir frente ao "problema" das assim chamadas periferias urbanas. Em época na qual muitas das práticas e das reflexões políticas sobre tais territórios e seus moradores são grandemente pautadas na chave das estratégias de gestão - sobretudo das "políticas públicas" de segurança e saúde - e das iniciativas cívicopedagógicas de "democratização da cultura" - por parte de organizações não governamentais e associações da sociedade civil -, cumpre esboçar um caminho de reflexão que contribua para a necessária problematização do esquema de legibilidade em que tais ações se inscrevem. Este, predominantemente, uma visão de viés "intervencionista" e "centrista" das dinâmicas sociais - no sentido de que estas são lidas na via de mão única de um Estado e de setores sociais portadores de saberes e práticas (im)postas à disposição de uma população tida, em sua maioria, como inoperante, inculta e, cada vez mais, perigosa.

A aludida "contramão" pela qual buscamos nos conduzir consiste, portanto, na simples, mas nem por isso fácil, tentativa de abordar a "periferia" a partir da positividade de alguns dos traços de politicidade pró- 
prios à sua dinâmica sociocultural. Isto é, uma abordagem que abandone o suposto primado normativo de certa institucionalidade política - do Estado, dos partidos, dos movimentos organizados, etc. - como "metro padrão" mediante o qual se mensura e se avalia o potencial de mobilização política dos grupos sociais. Trata-se de descentrar tais modalidades da ação política do lugar naturalizado de legitimidade que a práxis social hegemônica lhe confere e de se atentar para a necessidade de articular novas formas de legibilidade da política.

Afinal, parece bastante provável que a geração que chegou à idade adulta após as lutas por democratização - filhos e filhas da primeira geração de migrantes e operários que povoaram as periferias de cidades como São Paulo, cuja inserção social e econômica se deu fora dos setores sociais representados pelas principais forças partidárias de então, cujos horizontes profissionais foram configurados pelo desemprego, pela desregulação e informalidade, para nos restringirmos apenas a estas importantes mudanças - articule uma linguagem política outra daquela dos movimentos sociais da década de 1980.

Assim, a aposta analítica deste artigo é a possibilidade de ler as marginalidades sociais não como simples figurações do periférico, isto é, como imagens em negativo do centro - sejam quais forem os supostos atributos e competências que o preencham de significado social. O aspecto da dinâmica sociocultural da "vida nas periferias" de que, para tanto, nos munimos, é o RAP, forma estética tantas vezes desqualificada como "inculta", "grosseira", fruto da "incivilidade" proveniente da falta dos atributos que definem a "boa sociedade". O RAP, justamente por isso, talvez nos auxilie a pensar as margens como uma fronteira conflituosa em que se explicitam os limites e potencialidades de "velhas" e "novas" políticas. 


\section{Das margens...}

Pensar as dinâmicas sociais a partir de suas margens é uma perspectiva que há muito vem se colocando às Ciências Sociais. Desde Simmel, com suas "personagens" em posição de "estranhamento" a uma determinada ordem social, como o estrangeiro ou as prostitutas, passando por Foote-Whyte com os "rapazes de esquina" de Cornerville e chegando aos "párias de fronteira" pensados por Arendt, para ficarmos apenas nestes exemplos, o pensamento social e político tem revigorado o potencial heurístico dos "sujeitos marginais" (Feltran, 2010a). À semelhança do que realizara Foucault com sua galeria de "infames", não se trata de isolar sujeitos ou grupos da vida social mais ampla em nome de sua suposta especificidade que, por si, lançaria luz sobre sua condição. Ao contrário, trata-se de articular um olhar relacional que estabeleça os vínculos conflitivos através dos quais se constituem a norma e desvio, o familiar e o estranho, o legítimo e o ilegítimo, o centro e a periferia.

Tal perspectiva é um imperativo ainda maior quando se trata de abordar, como se pretende neste artigo, aspectos da dinâmica sociopolítica de uma metrópole como São Paulo. Como se sabe, o crescimento de São Paulo exibe paradigmaticamente a lógica de expansão urbana predominante na sociedade brasileira: o vínculo funcional entre especulação imobiliária, poder público e periferização, configurando a cidade como um território deflagrado em que centro e periferia, longe de serem espaços autônomos e independentes entre si, constituem figurações territorializadas de uma dinâmica social em que segregação e estigma, adesão e contestação estendem as tramas conflitivas em que se constituem e confrontam-se sujeitos.

Não por acaso, muito da reflexão sobre movimentos sociais em São Paulo direcionou seu enfoque às periferias, nelas buscando desvendar a configuração, mobilização ou debilidade dos sujeitos e da dinâmica 
política da cidade (Durham, 1973; Caldeira, 1984; Sader, 1988). Entretanto, diante das transformações ocorridas nas periferias durante as três últimas décadas (Feltran, 2010b), deve-se interrogar a respeito do potencial político que porventura resida na dinâmica social das "margens" de São Paulo. É neste sentido que este texto intenta uma breve reflexão sobre uma das manifestações, as quais, pelo menos desde os anos de 1990, se impõem mais intensamente na dinâmica cultural das periferias paulistanas: o movimento Hip-Hop, aqui enfocado em sua dimensão musical, o RAP ${ }^{1}$, mediante a análise de trechos de algumas composições do grupo paulistano Racionais $\mathrm{MC}^{\prime} \mathrm{s}^{2}$. A escolha deste material deve-se, por um lado, ao fato de o Racionais MC's ser o grupo de RAP brasileiro de maior repercussão no cenário midiático atual, o que tende a propiciar uma maior extensão ao debate e ao intercâmbio de ideias e de perspectivas analíticas diversas. Por outro lado e, sobretudo, pelo fato de que sua elaboração musical parece ter atuado como um dos principais fatores de articulação dos parâmetros de narratividade da "condição periférica" no contexto contemporâneo da produção cultural brasileira. Desigualdade social, racismo, violência, criminalidade são, sem dúvida, temas que informam outros grupos e artistas do RAP; entretanto, com uma recorrência e diversidade de abordagens poucas vezes comparável ao tratamento que

\footnotetext{
${ }^{1}$ RAP, sigla abreviativa do inglês rhythm and poetry, em português, "ritmo e poesia", em referência ao canto declamatório inscrito sobre a base rítmica de trechos de músicas alheias ou produzidos por sintetizadores. Além do elemento musical, o movimento Hip-Hop compreende o break, "dança de rua" que possui uma coreografia de gestos e movimentos abuptos, "quebrados"; e o "grafite", expressão gráfico-pictórica que se reapropria do espaço urbano mediante a conversão de suas superfícies em meio de inscrição de imagens.

${ }^{2}$ Integrado pelos MC's Mano Brown, Edy Rock, Ice Blue e pelo DJ KL Jay, o grupo de RAP Racionais MC's formou-se na segunda metade da década de 1980 e tem sua origem associada ao distrito periférico de Capão Redondo, zona sul da cidade de São Paulo, onde residiam alguns de sues integrantes. Sua discografia compreende os álbuns Holocausto Urbano (1990), Escolha o seu caminho (1992), Raio-X do Brasil (1994), Sobrevivendo no inferno (1997), Nada como um dia após o outro dia (2002) e Tá na chuva (2009).
} 
Ihes dispensam Mano Brown e Edy Rock, principais compositores do grupo. Essa perspectiva é ainda reforçada pela presença da articulação desses temas como parâmetros narrativos que extrapolam o RAP e marcam a tessitura literária de textos como os de Ferréz (2000), para não falarmos no romance de Paulo Lins (2003). Ademais, o modo pelo qual o grupo paulistano arma e modula as relações entre centro e periferia parece-nos especialmente adequado para a reflexão a que nos propomos.

Sendo assim, este texto move-se sobre uma questão de base: em que sentido a dinâmica cultural e a dinâmica política são coextensivas, isto é, qual é a politicidade própria ao cultural ou, de modo mais específico ao nosso propósito, quais relações podem existir entre a estética do RAP e a conflitualidade política presente na dinâmica urbana de São Paulo?

Longe de pretendermos uma resposta fechada a tais questões, o propósito é esboçar alguns apontamentos que permitam pensar a política nas periferias da atualidade. Isto é, pensá-la, em tempos em que a relação Sociedade Civil e Estado se modula menos pelo conflito característico do teor reivindicativo dos movimentos sociais dos anos 1980, e mais, por um lado, por dispositivos de gestão de populações e, por outro, pela capacidade reguladora do "mundo do crime", como instância normativa de regras de convívio (Feltran, 2010b), de formas de subjetivação e de atribuição de sentido ao social.

\section{Experiência coletiva, estética e política}

Em sua análise sobre a aparição de "novas personagens" na cena pública, Eder Sader (1988).aponta três processos coligados e simultâneos de constituição de sujeitos políticos: a existência de uma experiência compartilhada entre pessoas em condições e posições sociais semelhantes; a constituição de uma matriz discursiva capaz de circunscrever e significar 
esta experiência aos que nela se encontram envolvidos; a emergência de sujeitos de significação, isto é, de sujeitos que, por um lado, se constituem justamente na articulação entre a experiência compartilhada e a matriz discursiva que a enuncia, e, por outro, na prática de traduzi-las em reivindicações postas em confronto com o ordenamento do espaço público

Nestes termos, pensar o potencial político inscrito na estética do RAP implica pensar a conexão entre as dimensões políticas e as dimensões estéticas do processo de significação da experiência compartilhada. Em outras palavras, a estética do RAP configura um discurso capaz de circunscrever uma experiência compartilhada e, ainda mais, de confrontar o ordenamento do espaço público?

Na medida em que o processo de periferização fez-se acompanhar por um processo estigmatizante das populações periféricas e faveladas basta que se lembre da voga atual dos discursos da "violência urbana", articulados ao pânico de "insegurança" e à prática de incriminação da pobreza (Misse, 2006) - pode-se afirmar que na própria dinâmica urbana se inscreve um processo social de significação dos agentes que dela coparticipam. Portanto, a própria constituição da paisagem física e social da cidade opera o que Jacques Rancière (2005, p. 15, grifo do autor). denominaria partilha do sensivel:

Denomino partilha do sensível o sistema de evidências sensiveis que revela ao mesmo tempo, a existência de um comum e dos recortes que nele definem lugares e suas partes respectivas. Uma partilha do sensivel fixa, portanto, ao mesmo tempo, um comum partilhado e partes exclusivas. Essa repartição das partes e dos lugares se funda numa partilha de espaços, tempos e tipos de atividade que determina propriamente a maneira como um comum se presta à participação e como uns e outros tomam parte nessa partilha (Rancière, 2005, p. 15, grifo do autor).

Com efeito, trata-se de uma operação prévia à definição dos espaços institucionais que compõem o espaço público, e à seleção dos agen- 
tes que irão ocupá-lo. A ideia de partilha remete, assim, tanto à constituição de um vínculo entre os agentes que habitam um comum quanto à cisão entre eles, presente nas lutas pela demarcação dos limites externos deste comum (quais grupos serão admitidos ou barrados, quais serão deportados?) e pela demarcação de suas partes internas (como se definem as competências supostamente correspondentes à sua ocupação?). Nesse sentido, a dinâmica social aparece como uma zona litigiosa, cujos conflitos deslocam permanentemente a fronteira que circunscreve grupos e legitimidades, regulando as diversas pretensões ao político.

Portanto, os rappers, assim como seus "manos de quebrada", em decorrência de estigmas e estereótipos, encontram-se previamente deslegitimados à coparticipação do espaço político, condição reforçada ainda pelas restrições de acesso à cidade, decorrentes da segregação urbana e da desigualdade social, fatores que, somados, tendem a encolher a margem de sua visibilidade social. Isto é, os estigmas e estereótipos que pesam sobre as regiões e grupos periféricos são eles mesmos partes inscritas em uma certa partilha do sensível - aquela que, no mesmo passo, correlaciona o "centro" aos grupos e práticas hegemônicas e relega à "periferia" a "desordem", a "incivilidade" e o "crime". Uma partilha cujo "sistema de evidências sensíveis", para falar nos termos de Rancière, opõe as roupas largas, os bonés, blusões e correntes à vestimenta bem comportada dos "playboys" e "patricinhas", o "português correto" à "gíria de gueto", os barracos aos condomínios.

Entretanto, cumpre observar que grande parte da poética do RAP opera a desconstrução da máquina discursiva que produz a abjeção e a "inviabilidade" política e social das periferias. Parte constitutiva dessa máquina, o dispositivo policial/jurídico/penitenciário voltado à gestão de populações periféricas, articula e reproduz elementos do imaginário social, tais como "o criminoso" e "o pobre", e atualiza o estereótipo do "pobre criminoso" (Misse, 2006). Como nos adverte as errâncias de $O$ homem na estrada: 
Um mano meu tava ganhando um dinheiro,/tinha comprado um carro até rolex tinha!/Foi fuzilado a queima roupa no colégio, /abastecendo a playboyzada de farinha,/Ficou famoso, virou notícia, /rendeu dinheiro aos jornais, hã!, cartaz à policia/Vinte anos de idade, alcançou os primeiros lugares... /superstar do notícias populares!/Uma semana depois chegou o crack, /gente rica por trás, diretoria./Aqui, periferia, miséria de sobra./Um salário por dia garante a mão-deobra./A clientela tem grana e compra bem, /tudo em casa, costa quente de sócio./A playboyzada muito louca até os ossos!/vender droga por aqui, grande negócio (Brown, 1994).

Os versos procedem à suspensão de um dos procedimentos predominantes dos discursos estereotipados sobre a "periferia": a inteligibilidade pelo negativo e a homogeneização. Trata-se de ler os espaços e grupos periféricos pela chave da ausência e de generalizar esta leitura a toda extensão geográfica e social dos mesmos. Pode-se mesmo dizer que tais procedimentos são as faces complementares de uma única e perversa operação política e epistemológica. Significar o outro pela ausência é redundar o mesmo, é reafirmar o suposto primado ontológico do sujeito (hegemônico) sobre a alteridade (irredutível aos esquemas cognitivos daquele), convertida na mera falta dos caracteres que um eu (ou nós) supõe presentes em si. A homogeneização, por sua vez, é o resultado mais coerente que advém desta circularidade discursiva, paranoicamente girando em torno de si mesma para reencontrar, a cada nova significação, nada senão uma imagem de si.

Indiciando uma sociabilidade e lógica discursiva outra, a letra citada marca uma ruptura com essa racionalidade operante nos aparatos com que se defrontam os grupos periféricos. A miséria de sobra é a contrapartida do privilégio de poucos, duas das muitas faces da dinâmica social que permanece abastecendo a playboyzada de farinha. O varejo de drogas rivaliza o mundo formal-legal não só na disparidade de renda, gerando um salário por dia, como também no aspecto "empresarial", com gente fina por trás, diretoria e costa quente de sócio. Entretanto, a nota irônica, vender droga 
por aqui, grande negócio, deixa claro a partilha dos ganhos e dos riscos: não são os "playboys" ou os sócios costa quente que rendem dinheiro aos jornais ou cartaz à polícia, tampouco figuram como superstar do notícias populares. A errâncias dos versos entre o centro e a periferia (ou entre o "central" e o "periférico"), entre o pauperismo e a abundância, entre o legal e o ilegal, à semelhança dos rolex e carrões que deixam as ruas centrais e passam a circular pela favela, ao implodirem a tentativa de territorializar o fenômeno social global do narcotráfico no espaço circunscrito das periferias urbanas, implodem também a "evidência" das copertinências entre grupos e lugares, civilidade e incivilidade, legitimidade e ilegitimidade.

Assim, pode-se dizer que a letra, em alguma medida, logra circunscrever uma experiência compartilhada, na medida mesma em que confronta e ressignifica a experiência do estigma, simultaneamente aos solavancos que opera na partilha do sensível o qual configura o espaço público. Com efeito, O homem na estrada apresenta ao menos dois vetores que se oferecem à sondagem da potência política da estética do RAP: ressignificação e confronto, isto é, uma linguagem fortemente calcada em procedimentos de (re)apropriação e que revela uma incondicional disposição ao conflito. Admitindo que, ao menos nesse sentido estrito, talvez não seja exagero afirmar que o RAP guarda a potência de amarrar o vínculo entre a constituição do sujeito de significação estética e a do sujeito de significação política da experiência, resta, entretanto, esboçar o sentido desta virtual politicidade.

\section{"É tudo nosso": uma estética do sampler}

Em certo sentido, a dinâmica de expansão de São Paulo pode ser vista como uma lógica de expropriação elevada à enésima potência. Sistematicamente expulsos das áreas visadas pelo mercado imobiliário, os extratos empobrecidos dirigem-se às franjas do espaço urbano, relega- 
dos ao enfavelamento ou, na melhor das hipóteses, à autoconstrução em loteamentos periféricos, no mais das vezes, irregulares (Caldeira, 1984). A despeito de ter sido, do ponto de vista dos trabalhadores, o principal modo de efetivação do projeto familiar da casa própria, pode-se dizer que, do ponto de vista da "economia política da cidade", a autoconstrução os inseriu perversamente no processo de especulação imobiliária, ao mesmo tempo em que transferia a eles, sacrificando-lhes boa parte do tempo livre, parte dos custos - relativos à moradia - da reprodução da força de trabalho: expropriados pelo processo de produção econômica, expropriados pelo processo de expansão urbana.

Por um lado, essa observação importa, na medida em que permite compreender um modo de fazer que procede pela apropriação de elementos aparentemente disparatos, compondo, por justaposição, um conjunto que se encontra virtualmente em permanente estado de inacabamento:

Este processo [a autoconstrução] está relacionado, por exemplo, à formação de um certo tipo físico de espaço: é um dos grandes responsáveis pelo aspecto de colcha de retalhos que tem o bairro como um todo ou as suas casas. O material usado nas construções - blocos, cimento, lajes - e largura das ruas atestam que não se trata de uma favela, mas a maneira de construir as casas é muito semelhante, se não for idêntica: a agregação constante e sem um plano prévio definido, a partir do fundo do terreno, de espaços e detalhes, à medida que se vai conseguindo material - o que é obtido impõe os limites da improvisação (Caldeira, 1984, p. 108, grifo nosso).

Na feição de "colcha de retalhos" exibida pelo Jardim das Camélias em São Paulo - com as moradias se erguendo em parcelas, mediante o prolongamento de um cômodo ao outro, com a reutilização de materiais e de descartes, denotando certa provisoriedade no plano geral da construção, visto que o "projeto" se pautava no ritmo da disponibilidade dos recursos e de tempo livre -, assiste-se à articulação rudimentar de uma estética que opera a partir da condição de expropriação, remanejando-a 
e convertendo-a em possibilidade de outras formas de (re)apropriação do espaço. Por outro lado, a importância de tais observações reside na explicitação de tais rudimentos estéticos como traço constitutivo das estratégias adotadas pelos grupos periféricos em seu confronto com a lógica social e urbana em que se inseriam.

De modo análogo, no que respeita ao RAP, deve-se observar que o processo de expropriação urbana não se restringe a aspectos materiais e físicos do espaço. Pelo contrário, a partilha do sensível estende-se também, e talvez sobretudo, ao âmbito da circulação dos signos. Cabe lembrar que um dos sentidos debatidos por Veena Das e Deborah Poole do conceito de margem refere-se, justamente, a uma noção pertinente aos signos e a seus regimes de organização: legibilidade. Trata-se de apontar, em geral, a solidariedade entre o suposto primado da escrita sobre a oralidade, e, em particular, de certas gramáticas sobre "outras", e a constituição da burocracia escrita como elemento de inteligibilidade e controle do Estado sobre populações e territórios (Das; Poole, 2008). Neste sentido, a instituição da escrita, ao monopolizar os critérios e formas de legibilidade política da vida social, traça as margens que relegam amplos setores das populações periféricas à condição de portadores de linguagens errôneas e inoportunas. Expropria-se, portanto, grupos e universos culturais da legitimidade/legibilidade da capacidade de significação de seus discursos.

Com efeito, a recusa que os Racionais MC's endereçam à tentativa de enquadramento de sua linguagem na "gramática oficial" deixa entrever a alta voltagem de potencial político da estética do RAP. Em Negro Drama, asseveram: gíria não, dialeto! (Racionais Mc's, 2002). Afirmam, assim, a positividade de seu discurso diante da leitura negativa a que pretenderiam submetê-lo, reduzindo-o à pecha pejorativa de gíria, seja o código linguístico dos manuais escolares, sejam as estratégias taxionômicas dos registros burocráticos. Trata-se, portanto, de um dialeto, de afirmar um modo outro de se apropriar do código linguístico hegemônico e sub- 
metê-lo à recombinação, na mesma medida em que se desautoriza sua evidência. Algo semelhante se passa com a categoria "vagabundo". Se, por vezes, ela é empregada no sentido corrente de que foi revestida pelo mundo do trabalho e da moral hegemônicos, por outras, ela assume o caráter de saudação afetuosa entre "trutas" e parceiros musicais, indiciando uma estratégia de vida desdenhosa e emancipada do mundo de rotina e exploração dos "otários": se tiver que voltar pra favela, eu vou voltar de cabeça erguida, porque assim que é, renascendo das cinzas, firme e forte, guerreiro de fé! Vagabundo nato! (ibidem); Ou, ainda:

Nas ruas da Sul eles me chamam Brown,/Maldito, vagabundo, mente criminal/O que toma uma taça de champagne também curte/Desbaratinado, tubaína, tutti-frutti./Fanático, melodramático, bom-vivant,/Depósito de mágoa quem está certo é o Saddam, ham.../Playboy bom é chinês, australiano,/Fala feio e mora longe, não me chama de mano (Brown, 2002).

Vagabundo, assim, não como morosidade ou inércia, mas, pelo contrário, como potencial de vida e arte insubmissas, que resiste, vincula e solidariza os "manos da ponte pra cá"3.

Portanto, reapropriação, recombinação e ressignificação, numa palavra, sampler, eis uma das mais potentes armas políticas do RAP, assim como um de seus princípios estéticos centrais: no plano morfológico de construção das palavras - "fudidamente" (Rock; Brown, 1994), "afrodinamicamente" (Rock; Brown, 1992), "avonts" (Pixote; Blue, 2009), "playboyzada" (diversas letras); no plano sintático da composição das "canções" - ruídos de tiros para figurar o desenlace abrupto e truculento da trama de $O$ homem na estrada, secundados pela locução, em estilo notícia de jornal, lida em programa policial de rádio, ou televisivo: homem

\footnotetext{
${ }_{3}^{3}$ Título da música citada que se refere, provavelmente, à ponte João Dias que atravessa por sobre a via expressa Marginal Pinheiros, marcos urbanísticos de simultânea ligação e separação entre o centro e a zona sul da cidade de São Paulo.
} 
mulato aparentando entre vinte e cinco e trinta anos é encontrado morto na estrada do M'Boi Mirim sem número. Tudo indica ter sido acerto de contas entre quadrilhas rivais. Segundo a polícia, a vítima tinha vasta ficha criminal (grifo nosso). Ressalte-se, neste último item, a paródia, procedimento essencialmente dessacralizante, da escritura midiática, elemento conivente com a lógica de funcionamento da legibilidade burocrática enquanto dispositivo de significação e controle dos "marginais".

Portanto, o sampler, muito mais que artefato tecnológico, consiste em um dispositivo político de resistência à expropriação cultural e de subversão das fronteiras que partilham o audível e o inaudível, a música e o ruído, a gramática e o dialeto, o centro e a periferia. A máquina de reapropriação/ressignificação armada entre as pick-ups dos DJ's e o canto declamatório dos MC's recoloniza o universo de signos que circulam pela cidade, restitui, aos sem parte, a parte que aí lhes fora confiscada: reapossamento a um só tempo político e estético do discurso. Como sentencia a Canção de oração e Oya: traficar melodia, mais que o Abadia (Racionais Mc's; Sensação, 2009).

Deve-se atentar para o efeito estético de choque que os procedimentos de corte e colagem do RAP produzem na percepção musical. Parece se tratar de uma estética que revida, ao mundo, a agressão e a truculência que o mundo lhe dispensou (e dispensa). A intromissão dos ruídos da rua e do crime, harmonias de canções românticas convertidas em base para a narrativa de trajetórias trágicas - como é o caso de Ela partiu, da fase racional de Tim Maia, sampliada em $O$ homem na estrada- e a reutilização dos modos discursivos do jornal, televisão, rádio compõem essas (não)canções como uma colcha de retalhos, análogas à fragmentação social e física da metrópole. Estética e politicamente, do ponto de vista da percepção, esta forma de composição musical tende a obrigar a um alargamento da escuta, no sentido de que os cortes auditivos desferidos pelos versos e scrashes, como a incerteza dos becos e vielas, suspendem constantemente as expectativas 
perceptivas de um ouvido historicamente configurado pela continuidade linear de uma forma musical centrada na melodia. Neste ponto, além dos outros aspectos apontados, este solavanco no ouvinte, que o arranca do lugar comum confortável da redundância, conferem ao RAP uma virulência e agressividade que o configuram, por assim dizer, como uma poética que se situa em algum ponto entre o dissenso e a violência.

\section{Manos X Playboys}

Em 1976, na música Sala de recepção, gravada em seu segundo disco, Cartola indagava: habitada por gente simples e tão pobre/que só tem ao sol que a todos cobre/como podes, Mangueira, cantar? Após reativar a tradição romântica de exaltação da natureza, e convertê-la em meio de contrabalancear as desigualdades sociais, justificando assim a musicalidade vinda do morro, o compositor mangueirense, concluía: minha Mangueira, tu és a sala de recepção/aqui se abraça o inimigo/como se fosse um irmão. Nos anos 1990, MC Júnior e Leonardo, no funk Rap das armas, celebram: morro do Dendê é ruim de invadir/nós com os alemão vamos se divertir/por que no Dendê eu vou dizer como é que é/aqui não tem mole nem pra DRE. Em menos de meio século, assim, a tematização poética da relação "favela/ asfalto" passa por uma profunda e radical inflexão: o que era conciliação no samba de Cartola converte-se em confronto aberto no funks "proibidões". Transformação da estética musical, mas também, e sobretudo, transformação das relações sociais que a articulam. O RAP em geral, e os Racionais MC's, em particular, filiam-se, sem dúvida, a esta "segunda tradição", a do conflito, vazado, muitas vezes, nos termos da violência.

Se o RAP emerge de uma provável fissura, que cinde a sociedade brasileira entre grupos subalternizados e grupos hegemônicos, entre setores da sociedade civil e o Estado, há que se observar que a primeira 
e profunda dissenção que a estética do RAP operou foi, antes de mais, em relação à própria tradição da canção como forma musical popular historicamente predominante no Ocidente. Calcada na adequação entre palavra e melodia, de cuja convergência se configura o canto como linha melódica da composição (Tatit, 1994), a forma canção instaura o predomínio do melódico sobre o rítmico, da "contemplação" auditiva do intelecto sobre a movimentação motora do corpo. Embora tenha se firmado como a forma popular por excelência de expressão musical, contrapondo-se à exclusividade verbal da declamação e à exclusividade instrumental, características, respectivamente, da poesia e da música eruditas, a canção ainda conserva, assim, a binaridade alma/corpo, sobre a qual estas se firmaram. Assim, trata-se de uma forma estética ainda tributária da partilha que opõe e hierarquiza as binaridades que se desdobram desta primeira, tais como, letrado/iletrado, arte séria/entretenimento, intelectual/ingênuo, sofisticado/ rude, etc. O RAP, em sua própria forma estética, desestabiliza tais hierarquizações, pondo em questão, consequentemente, as assimetrias sociais que Ihes correspondem. A separação radical entre palavra e melodia, ou, mais rigorosamente, a virtual supressão do elemento melódico, e o predomínio do elemento rítmico, traduzem uma concepção musical que eleva o corpo e sua capacidade de ação à condição de núcleo estético da elaboração e percepção musical. Não se trata, redundando as hierarquizações que apontamos, de uma música "acéfala". Pelo contrário, trata-se da abertura de um outro horizonte cognitivo, em que a contemplação do espírito cede lugar à mobilização do corpo, e das relações dos corpos entre si, como dinâmica de significação do mundo e de ação sobre o mundo. O retraimento individual que caracteriza a elaboração e fruição estética desde o Romantismo, o mito do "gênio" criador, cedem lugar à explicitação do caráter coletivo da produção cultural, à aliança entre "trutas" e "quebradas" como relação em que se inscreve a heterogênese da elaboração musical. 
De um outro ponto de vista, a convergência estética canto-melodia remete ainda a uma sociabilidade de tendências conciliatórias. A estabilidade e linearidade que a canção confere ao discurso verbal corresponde a um regime de interações sociais pacificado e consensual o suficiente para que seja possível ao canto convocar os agentes ao cantar junto. Recorrendo ao refrão de uma conhecida canção dos anos 1990, deve-se observar que quando tudo é fácil, extremamente fácil/para eu, você e todo mundo/cantar junto ${ }^{4}$ é porque, diga-se de passagem, a rotina se sobrepõe à política, a redundância consensual se sobrepõe ao dissenso e ao conflito. Algo distinto se passa com RAP. A fragmentação operada tanto no plano verbal, quanto no musical, com a relativa dissociação entre ambos, a supressão do canto em favor da "declamação", remete a um regime de interações pouco afeito à adesão irrestrita a um hino, a um referencial de sentido que alinhave um consenso. O mundo do RAP é um mundo deflagrado, o qual, justamente por isso, guarda grande potencial de dissenso, seja frente à ordem estética, seja frente à política.

Com efeito, vão longe, senão cronologicamente, ao menos social e historicamente, os dias em que a lógica da mobilização política nas periferias era compatível à lógica estética de adoção de hinos, dias em que a luta era embalada pela já clássica canção de Vandré (Sader, 1988). Com efeito, estamos distantes dos anos 1980, e dificilmente se pode filiar o Hip-Hop, e o RAP em particular, aos movimentos sociais que surgiram durante aquela década. Mudanças de ordem política e institucional, assim como mudanças na própria dinâmica social das periferias são as linhas

\footnotetext{
${ }^{4}$ Trata-se de Fácil, composta por Wilson Sideral e Rogério Flausino e gravada em 1998 pelo grupo Jota Quest, canção, em certo sentido, emblemática da poética pop-rock que auferiu ampla expressão midiática durante os anos 1990: certo "bom-mocismo" satisfeito, vazado na morosidade de baladas românticas que contrastam com o inconformismo impetuoso de certas canções de bandas da década anterior como, entre outros exemplos, Titãs e Camisa de Vênus.
} 
de força que configuram tal distanciamento. Sem entrar nos pormenores de tais mudanças, cumpre observar que, nas últimas três décadas, os

parâmetros da experiência coletiva das periferias urbanas se deslocaram substantivamente [...] na etnografia em favelas e periferias da cidade tem sido possível reconhecer impactos causados tanto pelas mudanças na institucionalidade política quanto no mercado de trabalho, na família, na religiosidade, no consumo e no projeto de mobilidade social. A frustração da perspectiva de "integração" social da população desses territórios na dinâmica de "desenvolvimento" do Brasil é, portanto, inevitável. Nessa frustração, assumida como "realidade" pela geração jovem, é todo um projeto coletivo que deve ser revisto. E quando o projeto coletivo de "estar no mundo" se modifica, os atores tradicionais de representação desse projeto, como os movimentos sociais, são postos em questão. Se no cenário anterior a mediação das demandas das periferias ao mundo público podia ser feita por um dispositivo de tipo político - os "encaixes" entre movimentos sociais e as instâncias estatais de garantia de direitos -, a revisão dos conteúdos do projeto coloca em cena, e como protagonistas, outros dispositivos de mediação (Feltran, 2010b, p. 205-208, grifo do autor).

Sobre a modulação política da relação entre periferia e Estado, passa a predominar um modo de relação pautado pela gestão destas populações e territórios (ibidem), o qual, na dinâmica social das periferias, "rivaliza" com o fato de que

o "mundo do crime", antes considerado o oposto diametral dos "trabalhadores", surge recentemente como a atividade melhor remunerada e com alta disponibilidade de "postos de trabalho" para jovens de favela. Além disso, "o crime" passa a ser legitimado progressivamente como instância normativa e fiscal das regras de convívio (Feltran, 2010b, p. 207-208).

Assim, as periferias se constituem em um universo social cindido pela coexistência de duas ordens paralelas e opostas de regulação e legitimação das condutas e interações. Tais ordens reconfiguram os parâ- 
metros da experiência coletiva, das formas de constituição dos sujeitos e de elaboração de perspectivas de vida e visões de mundo (Silva, 2004; Misse, 2006,). Não seria exagero afirmar que a estética do RAP assume seus contornos mediante sua inscrição nesta nova configuração social. Na "canção" Pânico na zona sul, de seu primeiro disco, Holocausto urbano (1990), os Racionais MC's ainda lamentam o descaso oficial, aqui referido à agência estatal historicamente mais próxima destas populações, a polícia: quantos terão que sofrer pra se tomar providência/Ou vão dar mais algum tempo e assistir a seqüência (Brown, 1990). A demanda por uma ação "externa", que venha dar resolução ao holocausto urbano, é logo substituída por uma posição contrária, provavelmente decorrente das convicções oriundas da experiência das margens. É o que nos sugere O homem na estrada, já no disco seguinte, Raio-X do Brasil (1994): não confio na polícia, raça do caralho./se eles me acham baleado na calçada, /chutam minha cara e cospem em mim é.../eu sangraria até a morte.../ Já era, um abraço!./Por isso a minha segurança eu mesmo faço (Brown, 1994). Entretanto, a sugestão de adesão à lógica da violência privada, presente no último verso, é constantemente revista e reformulada, deixando entrever o caráter constitutivo que o tenso trânsito entre as cisões sociais desempenha na poética do R.A.P: Negro drama, de Nada como um dia após o outro (2002), assevera: falo pro mano, que não morra e também não mate (Racionais Mc's, 2002). E, no mesmo disco, veja-se a lógica que impera Da ponte pra cá: mas não leve a mal truta, cê não entendeu,/Cada um na sua função, o crime é crime e eu sou eu (Brown, 2002).

Assim, o RAP instaura uma dissensão em relação à institucionalidade política do Estado, assim como, ao contrário do que faria supor a agressividade de sua estética, em relação ao "mundo do crime". Entretanto, tais rupturas não resvalam para um "discurso de gueto", circunscrito aos limites do monólogo. Além de se dirigir constantemente aos "manos" de sua e de 
outras "quebradas", o RAP convoca a escuta de outros grupos e territórios. Em Negro drama, uma vez mais, o registro é abertamente o do conflito:

Disse que era bom e a favela ouviu,/La também tem whisky, e Red Bull, tênis Nike, fuzil,/Admito, seus carro é bonito, Hé, e eu não sei fazer/Internet, Video-cassete, os carro lôco,/Atrasado, eu tô um pouco se tô, eu acho sim, só que tem que/Seu jogo é sujo e eu não me encaixo,/Eu sou problema de montão, de carnaval a carnaval,/Eu vim da selva, sou leão, sou demais pro seu quintal,/Problema com escola, eu tenho mil, mil fita,/Inacreditável, mas seu filho me imita,/No meio de vocês, ele é o mais esperto,/ Ginga e fala gíria, Gíria não dialeto/Esse não é mais seu, Hó, subiu,/Entrei pelo seu rádio, tomei, se nem viu,/Mais é isso ou aquilo, que Senão dizia,/Seu filho quer ser preto, Rá, que ironia,/Cóla o pôster do 2 Pac aí, que tal, que se diz,/Sente o Negro Drama, vai/ Tenta ser feliz" (Racionais Mc's, 2002, grifo nosso.)

Mais uma vez, como se observou em $O$ homem na estrada, suspendem-se as territorializações do "centro" e da "periferia", com a importante diferença de que, agora, inverte-se o esquema valorativo entre ambos. A positivação da condição "periférica" é lançada contra a posição "central", que se vê deslocada do conforto de seu sentido social previamente instituído, mediante sua colonização pelos signos do "submundo" urbano. Os manos se recusam ao jogo dos playboys e Ihes devolvem os expedientes de desqualificação simbólica, conflito modulado na forma de um desafio: vai, tenta ser feliz.

Talvez a síntese poética mais representativa deste simultâneo dissenso em relação à ordem legal e à ordem do "crime", assim como da tensão conflitiva presente nas relações com o mundo "para lá da ponte", seja a equalização simbólica que o RAP opera entre as palavras - signo liberal-iluminista da Democracia - e as armas - signo tanto do conflito e da luta por transformações quanto da violência: ninguém quer ouvir a 
nossa voz/cheia de razões calibres em punho (Brown, 1990); a informação é uma grande arma/mais poderosa que qualquer PT carregada (Rock; Brown, 1992); não quero te matar, somente te alertar lapenas uma frase pode te derrubar./uma frase feita com sabedoria, /scrash, batidas e rimas (Racionais Mc's; Thaíde, 2009). Oriunda, por um lado, da falência histórica do projeto de integração social e de expansão da cidadania mediante o assalariamento, e, por outro, do esvaziamento da politicidade da relação sociedade civil e Estado, em grande parte convertida na gestão de "políticas de segurança", sobrevivendo à violência privada do "mundo do crime" e à violência pública dos aparelhos de Estado, a gramática política do RAP não fala a língua da ordem institucional-legal, dos movimentos, partidos, eleições, órgãos estatais, tampouco a da sociabilidade violenta em processo de intensificação ${ }^{5}$. Ao contrário, apropria-se de ambas, sem que coincida totalmente com nenhuma delas. Mescla de conflito político e agressividade, a ressignificação da política pelo crime - palavras convertidas em armas - e do crime pela política - armas convertidas em palavras - deixa entrever o fio da navalha em que se equilibra o potencial político da dinâmica social das periferias contemporâneas. A esfera pública evocada pelo RAP, portanto, não rende tributo à estatização da política, não aposta em setores "bem intencionados" da sociedade civil, tampouco derrapa na mitificação messiânico-vingadora do crime. Seja qual for a positividade que aí se principia, de contornos apenas esboçados, o potencial de conflito implicado nos arroubos estéticos de agressividade, a disposição ao dissenso frente à ordem comum das coisas e dos signos, descerram um horizonte em que se impõe a (re)politização do discurso estético e a ressignificação da ação política.

\footnotetext{
${ }^{5}$ Ordem institucional-legal e sociabilidade violenta são conceitos elaborados por Silva (2004) e retomados por Misse (2006), na interpretação da cisão da dinâmica social brasileira pela coexistência de ordens autônomas e opostas de legitimidade.
} 


\section{Considerações finais: RAP, uma fronteira poética}

Tomando de empréstimo a perspectiva analítica de Candido (2006), pode-se dizer que a relação social que o RAP internaliza, relação que estrutura e faz funcionar sua estética, é aquela que se arma na oposição conflitiva entre "manos" e "playboys". Inscrita na própria dinâmica socioespacial de São Paulo, esta relação - e seus desdobramentos, "centro"/"periferia", "legitimo"/"ilegítimo", "legalidade"/"ilegalidade" configura, senão o único, ao menos um dos referenciais simbólicos que articulam a politicidade desta forma estética. Em outras palavras, trata-se da relação em cujo interior, por um lado, se circunscreve uma experiência compartilhada pelas populações periféricas; por outro, se produz um discurso capaz de explicitar e revestir de significado essa mesma experiência; e, por fim, ponto de interseção entre estes dois processos, emergem sujeitos que articulam um ao outro.

De certa forma, a simultaneidade entre tal relação, seus conflitos e as estratégias que deles decorreram já estavam presentes desde "os primórdios" do RAP Os encontros na estação de metrô São Bento, no centro de São Paulo (Gimeno, 2009), para rimar, dançar, cantar e ouvir música, no vai-e-vem entre a casa e o trabalho, o "sistema" e o "lazer", já colocava em cena as errâncias entre o "centro" e a "periferia", as reapropriações/ ressignificações do espaço urbano de que aqueles jovens pauperizados, subempregados, ou apenas "de rolê", lançavam mão como estratégia de inserção na vida da metrópole.

Desta "cena inaugural", desprende-se mais um aspecto que, talvez, não tenha sido devidamente explicitado até aqui: a ligação congênita entre o RAP e o proceder, o modus vivendi, da geração que, obrigada pelas circunstâncias, cresceu contrariando a estatística (Rock; Blue; Brown, 1997), como advertem os Racionais MC's em seu Capítulo 4, versículo 3.

Nesse sentido, se o RAP, tal como intentamos mostrar, tangencia fronteiras de ordens diversas, é porque ele mesmo, enquanto estética, 
inscreve, nos conflitos da dinâmica social, uma fronteira simbolicamente habitada e percorrida pelos "manos". Mesmo que o potencial político deste, e de outros aspectos apontados, seja algo ainda por se explicitar, é certo que, se a supressão da história de segregação e estigma está além de suas possibilidades, o RAP, ao menos, reconfigura parâmetros de narratividade - no caso, os da cidade - condição primeira da luta contra toda e qualquer subalternidade (Spivak, 2010). Nesta (re)invenção de um outro pertencimento à metrópole, no esboço de um novo traçado para o comum, de contornos necessariamente indefinidos, posto que em permanente litígio, não residiria um dos sentidos - fortes - de democracia?

\section{Referências}

1. BROWN, Mano. Intérprete: Racionais MC's. Da ponte pra cá. In: Racionais MC's. Nada como um dia após o outro dia. São Paulo: Cosa Nostra, p2002. 2 CDs. Disco 2, faixa 9.

2. BROWN, Mano. Intérprete: Racionais MC's. O homem na estrada. In: Racionais MC's. Raio-X do Brasil. São Paulo: Zimbabwe Records, p1994. 1 CD. Faixa 4.

3. BROWN, Mano. Intérprete: Racionais MC's. Pânico na zona sul. In: RACIONAIS MC'S. Holocausto Urbano. São Paulo: Zimbabwe Records, p1990. 1 CD. Faixa 1.

4. CALDEIRA, Teresa Pires de Rio. A Política dos Outros: o cotidiano dos moradores da periferia e o que pensam do poder e dos poderosos. São Paulo: Brasiliense, 1984.

5. CANDIDO, Antonio. Crítica e Sociologia. In: CANDIDO, Antonio. Literatura e Sociedade. 9. ed. Rio de Janeiro: Ouro sobre Azul, 2006. p. 13-26.

6. DAS, Veena; POOLE, Deborah. El estado y sus márgenes. Etnografías comparadas. Cuadernos de Antropología Social, Buenos Aires, n. 27, p. 19-52, jan./jul. 2008.

7. DURHAM, Eunice Ribeiro. A caminho da cidade. São Paulo: Perspectiva, 1973.

8. FELTRAN, Gabriel de Santis. Introdução. Lua Nova Revista de Cultura e Política, São Paulo, n.79, p. 9-13, 2010a.

9. FELTRAN, Gabriel de Santis. Margens da política, fronteiras da violência: uma ação coletiva das periferias de São Paulo. Lua Nova Revista de Cultura e Política, São Paulo, n.79, p. 201-233, $2010 b$.

10. FERRÉZ. Capão Pecado. São Paulo: Labortexto Editorial, 2000. 
11. GIMENO, Patrícia Curi. Poética versão: a construção da periferia no rap. 2009. 169 f. Dissertação (Mestrado em Antropologia Social) - Instituto de Filosofia e Ciências Humanas, Universidade de Campinas, Campinas.

12. LINS, Paulo. Cidade de Deus. São Paulo: Companhia das Letras, 2003.

13. MISSE, Michel. Crime e Violência no Brasil Contemporâneo: estudos de sociologia do crime e da violência urbana. Rio de Janeiro, Lumen Juris Editora, 2006.

14. PIXOTE, Dom; BLUE, Ice. Intérprete: Racionais MC's; Dom Pixote. O inimigo é de graça. In: Racionais MC's. Tá na chuva. [S.I.: s.n.]. p2009. 1 CD. Faixa 5.

15. RACIONAIS MC'S. Intérprete: Racionais MC's. Negro drama. In: Racionais MC's. São Paulo: Cosa Nostra, p2002. 2 CDs. Disco 1, faixa 4.

16. RACIONAIS MC'S; SENSAÇÃO. Intérprete: Racionais MC's; Sensação. Canção de oração e Oya. In: Racionais MC's. Tá na chuva. [S.I.: s.n.]. p2009. 1 CD. Faixa 3. 17. RACIONAIS MC'S; THAÍDE. Intérprete: Racionais MC's; Thaíde. Quem procura acha. In: Racionais MC's. Tá na chuva. [S.I.: s.n.]. p2009. 1 CD. Faixa 4.

18. RANCIÈRE, Jacques. A partilha do sensível: estética e política. São Paulo: Exo experimental org; Ed. 34, 2005.

19. ROCK, Edy; BLUE, Ice; BROWN, Mano. Intérprete: Racionais MC's. Capítulo 4, versículo 3. In: Racionais $M C^{\prime}$ s. Sobrevivendo no inferno. São Paulo: Cosa Nostra, p1997. 1 CD. Faixa 3.

20. ROCK, Edy; BROWN, Mano. Intérprete: Racionais MC's. Fim de semana no parque. In: Racionais MC's. Raio-X do Brasil. São Paulo: Zimbabwe Records, p1994. 1 CD. Faixa 1.

21. ROCK, Edy; BROWN, Mano. Intérprete: Racionais MC's. Negro limitado. In: Racionais MC's. Racionais MC's. São Paulo: Zimbabwe Records, p1992. 1 CD. Faixa 2. 22. ROCK, Edy; BROWN, Mano. Intérprete: Racionais MC's. Voz ativa. In: Racionais MC's. Escolha o seu caminho. São Paulo: Zimbabwe Records, p1992. 1 CD. Faixa 1.

23. SADER, Eder. Quando novos personagens entram em cena: experiências, falas e lutas dos trabalhadores da Grande São Paulo. Rio de Janeiro: Paz e Terra, 1988.

24. SILVA, Luiz Antonio Machado da. Sociabilidade violenta: por uma interpretação da criminalidade contemporânea no Brasil urbano. Sociedade e Estado, Brasília, v. 19, n 1, p. 53-84, jan./jun. 2004.

25. SPIVAK, Gayatri. Pode o Subalterno Falar? Belo Horizonte: Ed. UFMG, 2010. TATIT, Luiz. Semiótica da Canção: melodia e letra. São Paulo: Escuta, 1994.

Recebido em: 10/01/2012

Aceite final: 05/03/2012 